\title{
Moving healthcare professionals - a whole system approach to embed physical activity in clinical practice
}

\author{
Michael Brannan ${ }^{1}$, Matteo Bernardotto ${ }^{2^{*}}$, Nick Clarke $^{1}$ and Justin Varney ${ }^{3}$
}

\begin{abstract}
Background: Healthcare professionals are key informants to support individual behaviour change, and although there has been some progress in empowering clinicians to promote physical activity and health at work, an effective strategy overarching the whole medical educational journey is still lacking. This report provides an overview from the Moving Healthcare Professionals programme (MHPP), a whole-system educational approach to embed prevention and physical activity promotion into clinical practice.

Methods: The MHPP model integrates educational resources into three core domains of medical education: undergraduate education, postgraduate education and continuing professional development. The interventions are designed to spiral through existing educational approaches rather than as additional special study modules or bolton courses, thus reducing self-selection bias in exposure. Interventions include spiral undergraduate education materials, e-learning, embedded post-graduate resources and face-to-face peer-to-peer education.

Results: To date the MHPP model has been applied in two key areas, physical activity and health and work. The physical activity programme in a partnership between Public Health England and Sport England has delivered face-to-face training to 17,105 healthcare professionals, embedded materials in almost three quarters of English medical schools and overseen >95,000 e-learning modules completed over two and half years. Evaluation of the individual elements of the model is ongoing and aims to show improvements in knowledge, skills and practice. Further evaluation is planned to assess patient impact.

Conclusions: The MHPP model offers a coherent whole-system approach to embed public health action into existing healthcare education models, and as such provides a framework for rapid change as well as upstream implementation to support the clinicians of today and tomorrow.
\end{abstract}

Keywords: Whole system approach, Medical education, Physical activity, eLearning

\section{Background}

There is substantial evidence supporting the positive impact of behavioural interventions to promote physical activity and healthy lifestyle [1]; however, there is also a need for more effective programmes and collaborations [2]. At present, healthcare professionals appear to be struggling to deliver these messages, and response from patients has been mixed [3]. In fact, both adult and older patients often feel they are not receiving physical activity

* Correspondence: Matteo.Bernardotto@nhs.net

${ }^{2}$ Imperial College Healthcare NHS Trust, London, UK

Full list of author information is available at the end of the article interventions or guidance from their general practitioners (GPs) [4, 5].

Research has shown that primary healthcare professionals such as GPs already frequently discuss physical activity with their patients, although this advice is typically brief, non-specific and therefore fails to capitalise on the opportunity to change patients' behaviour and engagement with a more active lifestyle [6]. However, even within medical specialities there is a significant individual inter-clinician variability on how exercise and physical activity is prescribed to specific patient groups, for instance with cardiovascular comorbidities, which highlights the lack of standardisation and recognised guidance [7].

(c) The Author(s). 2019 Open Access This article is distributed under the terms of the Creative Commons Attribution 4.0 International License (http://creativecommons.org/licenses/by/4.0/), which permits unrestricted use, distribution, and reproduction in any medium, provided you give appropriate credit to the original author(s) and the source, provide a link to the Creative Commons license, and indicate if changes were made. The Creative Commons Public Domain Dedication waiver (http://creativecommons.org/publicdomain/zero/1.0/) applies to the data made available in this article, unless otherwise stated. 
Furthermore, interventions are generally on a single encounter basis and are often inadequate in driving change in physical activity engagement and function [8]. There is therefore a great need for both GPs and physicians to be effectively trained to promote physical activity and prescribe exercise $[9,10]$. Recent surveys found that many physicians, including newly qualified doctors, lack the confidence to deliver physical activity counselling; and despite changes in national guidelines in the United States (US), counselling behaviour has not increased [11]. At undergraduate level, in English medical schools there is widespread lack of training on physical activity promotion [12]. Among other healthcare professionals such as physiotherapists, research has shown some improvement in their understanding of physical activity counselling [13], but there is still generalised poor understanding [14] and wide-spread unawareness about the current physical activity recommendations [15].

On the other hand, patients may have unrealistic expectations about what healthcare professionals can deliver in terms of physical activity counselling, which in itself is a significant barrier to successful intervention [16]. In primary care this barrier to integrate physical activity promotion is compounded by reported lack of time, skills, cost reimbursement, as well as adequate screening [17]. In addition, the lack of co-ordinated large scale initiatives reduces the impact of any intervention. There is a need not just for better community-based collaborations with sport, leisure and fitness providers [18], but also the improved infrastructure, such as access to walking or biking, that was shown to define effective population-level interventions [19].

Despite the challenges physical activity promotion remains a cost effective and viable option of health promotion and prevention [20], and in fact, primary care work force and GPs are probably the most cost-effective healthcare professionals to deliver physical activity counselling [21]. However, attitudes and behaviours among healthcare professionals are influenced from the early career stages, as the confidence in delivering physical activity interventions among medical students and doctor is associated with their own personal exposure and engagement with physical activity [22]. In order to address the specific needs of different healthcare professionals, the Moving Healthcare Professional Project (MHPP) was developed as an overarching model capturing all stages of medical education, from undergraduate and postgraduate to continuing medical education. It has been shown to have the potential to drive and embed cultural changes within the health professions that could significantly improve the quality of physical activity counselling and promotion [23, 24]. This study looks at the early implementation of the MHPP in the England and its ongoing development.

\section{Methods}

The moving healthcare professional Programme (MHPP)

The MHPP is based on a simplified pathway of medical education, where individuals move from undergraduate education into a period of post-graduate structured training and education, followed by ongoing continuing professional development (CPD) once working within a defined specialism. Within each of these three stages there are structured educational components (e.g. undergraduate curriculum and teaching resources), and the MHPP model was developed to embed within these components (Fig. 1).

The programme model was initially developed for physical activity through a series of workshops with key national stakeholders, including medical school deans, medical royal colleges and other healthcare professional bodies, medical trade unions and front line clinicians. This facilitated the development of specific peer-to-peer training and e-learning modules to deliver the MHPP. Some components of the programme were already in development for other projects, such as the spiral medical undergraduate teaching materials on physical activity, so there was a synergistic opportunity to integrate them as the MHPP evolved. The programme was initially piloted in one region (London) and then expanded nationwide throughout England for physical activity over two years; this approach was then mirrored for health and work.

\section{The physical activity MHPP}

The initial pilot for the MHPP was focused on delivering physical activity education to doctors in partnership with Sport England. An overview of programme's development timeline is shown in Table 1 . The programme has four core components:

\section{Undergraduate spiral education materials}

The spiral teaching resources are a suite of 22 slides and teaching notes that can be integrated into core curriculum teaching, (i.e. slides on physical activity and hypertension can be integrated into a general lecture on hypertension). The slides were developed by an international collaboration of medical educationalists and academics and validated by the Council of Medical School deans. Alongside the teaching materials a suite of 150 multiple-choice questions were also developed. The resources are free to use in England and are managed by "Exercise Works".

\section{Postgraduate embedded educational resources}

This element has been developed and led by the Faculty of Sport and Exercise Medicine (FSEM), providing interactive educational materials tailored to different clinical 


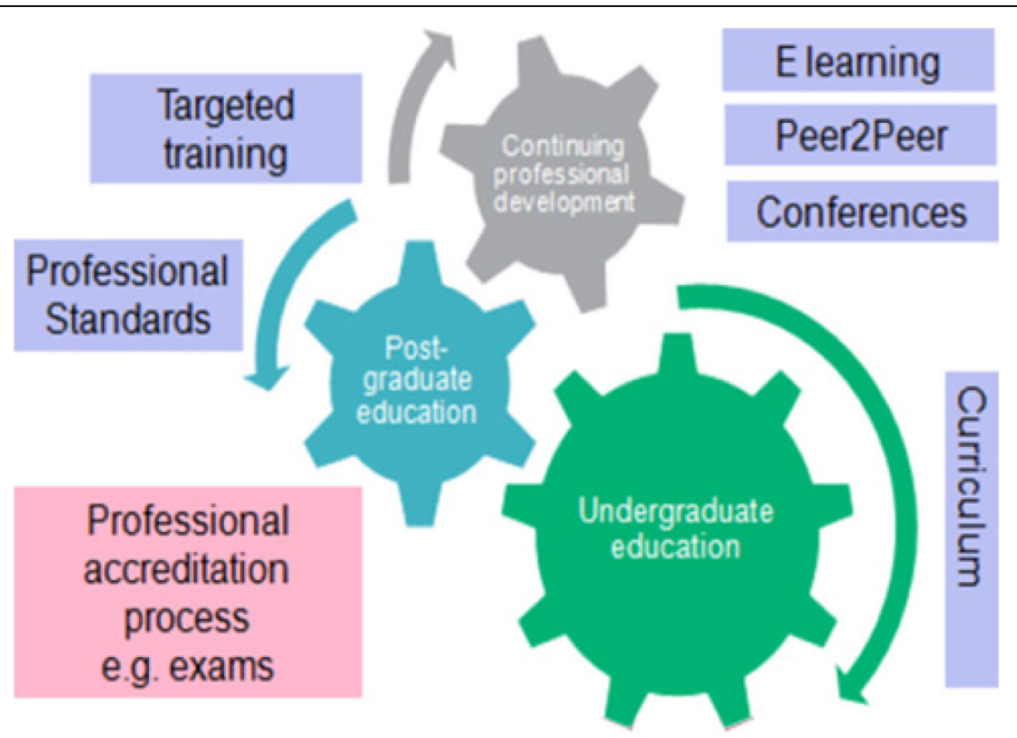

Fig. 1 "Moving Professionals - The model". Cog diagram showing the overview of the MHPP

specialisms and embedding them within the relevant Medical Royal College website and curricula.

3. Continuing professional development e-learning resources

A suite of nine e-learning modules were developed on the British Medical Journal (BMJ) e-learning platform chosen because of its unique reach to doctors and its credibility as a medical CPD provider. Alongside the core modules an additional module on motivational interviewing techniques was also developed.

4. Face to face peer educators (clinical champions)

Clinical Champions are healthcare professionals who are paid on a sessional basis to deliver a standardised training package which has been peer reviewed and sponsored by Public Health England (PHE). Clinical champion training is delivered directly to healthcare professionals and where possible the standardised package is supplemented with information on the local physical activity programmes to encourage signposting.

In parallel to the core programme components, there was also work to develop the Chief Medical Officers guidelines on physical activity at different lifecourse stages into infographics which were integrated into the educational resources and disseminated as supplements in the BMJ, an article in the British Journal of Sports Medicine (BJSM), conferences, media events and press releases.

\section{Ethics}

The MHPP was approved by Public Health England Research Ethics Committee (PHE REC). The data presented in this manuscript was collected after obtaining

Table 1 BMJ eLearning modules usage from January 2014 to April 2018

\begin{tabular}{lllll}
\hline \multicolumn{2}{l}{ Module title } & Started & Completed & Completion ratio \\
\hline 1 & Importance of physical activity & 14,544 & 13,611 & $94 \%$ \\
2 & How physical activity produces health benefits & 10,001 & 9435 & $94 \%$ \\
3 & The health Benefits of physical activity: cancer & 12,108 & 11,576 & $96 \%$ \\
4 & The health benefits of physical activity: cardiovascular disease & 11,517 & 10,839 & $94 \%$ \\
5 & The health benefits of physical activity: depression, anxiety and sleep & 11,595 & 10,763 & $93 \%$ \\
6 & The health benefits of physical activity: diabetes & 15,586 & 14,548 & $93 \%$ \\
7 & The health benefits of physical activity: osteoarthritis and low back pain & 10,924 & 10,418 & $95 \%$ \\
8 & The health benefits of physical activity: promoting physical activity in primary care & 9484 & 8868 & $94 \%$ \\
9 & The health benefits of physical activity: respiratory disease & 9555 & 9077 & $\mathbf{9 5 \%}$ \\
Total & & & $\mathbf{1 0 5 , 3 1 4}$ & $\mathbf{9 9 , 1 3 5}$ \\
\hline
\end{tabular}


informed written consent from all participants that completed eLearning modules and/or face-to-face training as part of the MHPP.

\section{Results}

\section{Timeline}

Since its first implementation in 2014 the MHPP has significantly expanded and addressed the four core components of the physical activity modules. When the Clinical Champions model was initially piloted, a single GP trained as a clinical champion was funded to deliver physical activity training using a standardised set of teaching slides. Since then, the Clinical Champions have grown in number and continue to deliver training to nationwide to doctors, nurses and allied healthcare professionals. In parallel, spiral curriculum resources developed by "Exercise Works" and Nottingham Medical School were gradually implemented across medical school curricula. Furthermore, a suite of 9 e-learning modules to deliver CPD were developed and peer-reviewed for the BMJ e-learning platform. A chronological overview of the programme's development and implementation is shown in Fig. 2.

\section{Undergraduate education}

A target of 35 English medical or health schools has been commissioned by PHE to achieve the MHPP's undergraduate education goals. To date, 26 (74\%) medical schools have agreed to implement physical activity modules and education into undergraduate curricula or have done so already. Further evaluation is being undertaken to understand the barriers and enablers for integration of the resources, and whether those not actively using the resources have alternate similar material already embedded across their curricula.

\section{eLearning resources}

In collaboration with BMJ Learning an online course on physical activity in the treatment of chronic condition was launched in October 2014 [25]. The course comprises 9 separate modules covering physical activity for different conditions, from mental health to diabetes and cancer, totalling 4 and half hours of recognised CPD activity. Since its inception $>95,000$ eLearning modules have been completed (Table 1) by healthcare professionals from diverse specialisms and professional groups, despite the platform being primarily targeted at doctors. Qualitative feedback on the modules from participants through the platform feedback survey has been very positive.

\section{Postgraduate face-to-face education}

Postgraduate education has been driven by the Clinical Champions programme, where peer training on physical activity counselling and exercise prescription is delivered directly to practicing healthcare professionals in the form of recognised CDP modules. This branch of the MHPP has impacted to date an estimated 17,105 healthcare professionals (Table 2) and there has been good geographical coverage as there has been a core of champions delivering training in each of PHE's nine regions. Although it is not possible from the routine data

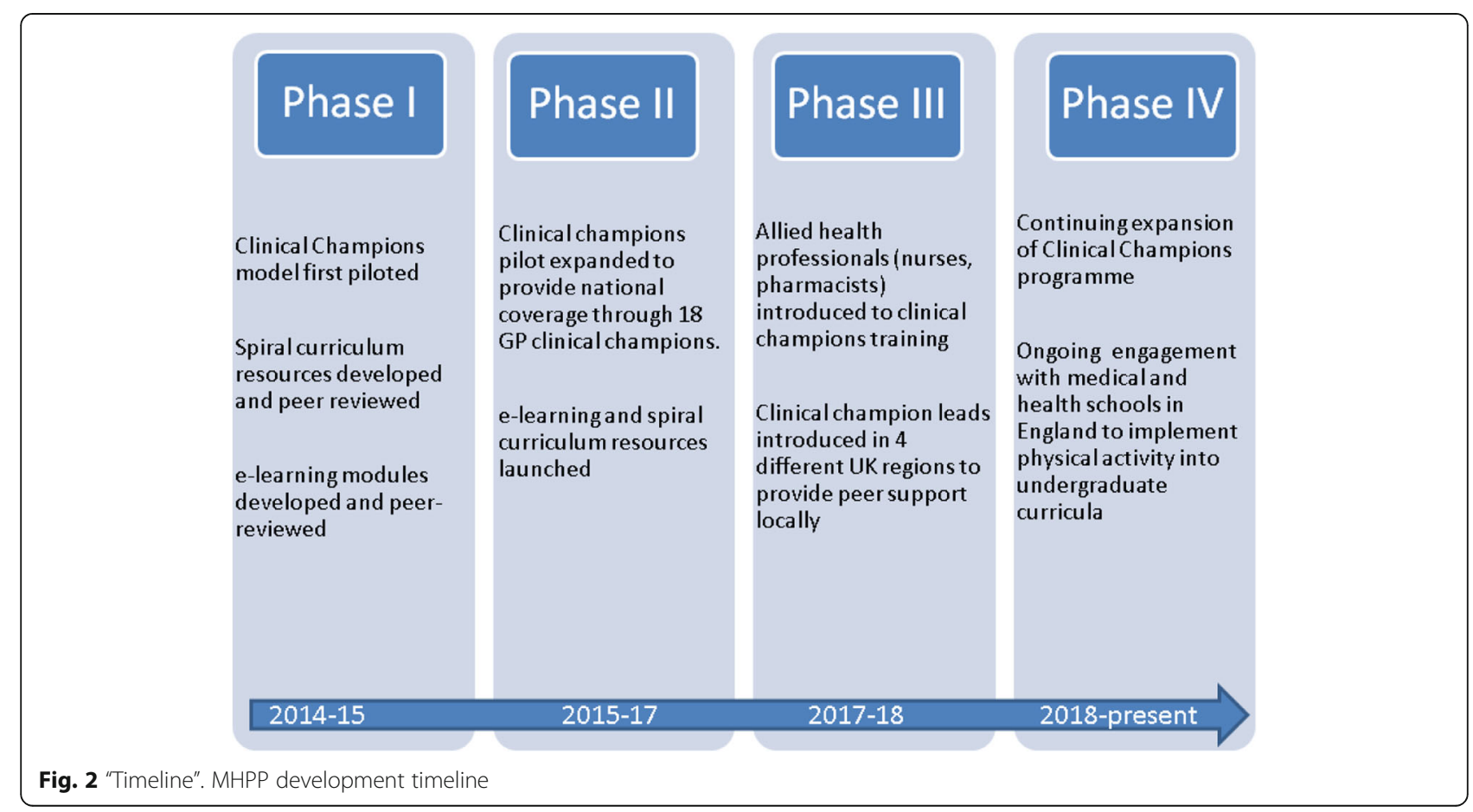


collection to judge how much overlap there is between different strands of the programme we would expect there to be a strong element of cross-pollination with the e-learning materials to reinforce the face to face teaching.

The evaluation of the clinical champion's programme is currently being undertaken. However, in line with the results from the initial pilot, it should hopefully be able to demonstrate a positive impact on clinicians' knowledge about physical activity in both primary and secondary prevention, as well as more confidence in integrating brief advice on physical activity into routine consultations.

\section{Discussion}

Considering the World Health Organisation (WHO) predicts that by 2020 two thirds of disease burden worldwide will be due to poor lifestyle choices [26], interventions to introduce lifestyle medicine teaching into undergraduate and postgraduate health education are expected to have a significant public health impact [27] and are in line with the WHO global action plan on physical activity (GAPPA) to reduce the prevalence of sedentary lifestyles [28]. In this context, the MHPP model is a coherent, co-produced whole system educational approach to embed effective physical activity counselling into routine clinical training and ultimately everyday clinical practice. It presents a viable and transferrable model for change that can be replicated for different topics and challenges, and its use of different learning styles and preferences across the professional "lifespan" ensures comprehensive coverage. Ultimately, the MHPP provides a framework for change that we hope will underpin a step change in the approach to physical activity in clinical practice in England for today and tomorrow's healthcare professionals.

Table 2 Activity data on Programme Strands, (HCA healthcare Assistant, HCP healthcare professional)

\begin{tabular}{|c|c|c|}
\hline Phase & Number trained & Detailed audience breakdown ${ }^{a}$ \\
\hline Phase 1-2014/15 & 217 & $217 \mathrm{GP}$ trainees \\
\hline Phase 2-2015/16 & 5156 & $\begin{array}{l}2199 \text { GPs } \\
1738 \text { Other doctors } \\
1132 \text { Nurses } \\
87 \text { HCAs and other HCPs }\end{array}$ \\
\hline Phase 3-2016/17 & 4959 & $\begin{array}{l}2041 \text { GP } \\
1386 \text { Trainee GP } \\
1380 \text { Other HCP } \\
152 \text { Trainee other HCP }\end{array}$ \\
\hline Phase 4-2017/18* & 6773 & $\begin{array}{l}2381 \text { GPs \& HCPs } \\
1273 \text { Trainee GPs \& HCPs } \\
3119 \text { Nurses }\end{array}$ \\
\hline Grand total & 17,105 & \\
\hline
\end{tabular}

ap to end of February 2018
MHPP was designed to take a whole educational system approach to embed physical activity into clinical practice, including the upstream integration in undergraduate education as well as the downstream capability development with qualified healthcare practitioners. The core interventions focused on undergraduate, postgraduate and peer-to-peer education as well as eLearning, which were chosen as no single educational approach used in isolation has been shown to provide effective and enduring changes among healthcare professionals $[7,8,11]$. These core elements were supported by a consistent public health awareness campaign reiterating the importance of physical activity advice from clinicians. By taking this "whole educational life" approach, the model is designed to eventually become redundant as the clinical social norm shifts toward the routine integration of brief advice on physical activity into daily clinical practice for all clinicians in England.

The MHPP's implementation of spiral education into undergraduate curricula addresses the inconsistent education on physical activity counselling and exercise prescription that healthcare students receive [12, 22]. In addition, the postgraduate curricula changes driven by FSEM also address the perceived lack of adequate training among trainee doctors, who report poor knowledge, skills and competence to provide patient-centred exercise counselling and exercise prescription [29]. Spiral integration was chosen as an established approach used successfully to embed a common message across multiple different topics and learning experiences [30], reducing the risk that the message only reaches those who are already motivated, thus continually reinforcing the benefits of physical activity across multiple disease conditions and in the context of both prevention and treatment of disease.

The inclusion of a large eLearning component is in line with previous research supporting the use of this modality among medical students, where a large meta-analysis of 59 studies showed equivalent satisfaction and effectiveness when compared with traditional teaching methods [31], and also reflects the growing trend to deliver postgraduate medical education for busy healthcare professionals through e-learning. The MHPP builds on this with a multi-faceted model that implements eLearning alongside face-to-face training, which has been shown in different studies to be both practical and cost-effective in helping healthcare professionals deliver a self-management support programme and physical activity counselling to chronically ill patients [3234]. The peer education 'champions' focused on delivering training through existing programmed teaching time which was especially effective in reaching GPs but also provided a recognisable context for CPD training. This approach was further strengthened by having 'peer 
educators' who could relate the theory to practical case studies and share tips and hints for the practical application of the evidence. The use of trained healthcare professionals ("Clinical Champions") to deliver capillary training on physical activity counselling and prescription is not only a novel approach built on the best evidence available, but also a strategy that addresses the limitations of models based solely on eLearning [35].

Taking a whole educational system approach to embed cultural change in medical education is complicated and requires strategic horizon scanning as well as well-resourced implementation and delivery. In addition, like all novel interventions, it comes with challenges as well as limitations. The MHPP has benefited from having PHE, the national public health agency responsible for England, to act as pivot between all key national partners involved in developing a whole new educational system. Nonetheless, a public health body in isolation is not sufficient in itself to deliver these wide-ranging changes, and the MHPP represents a feasible and synergistic co-production model where other healthcare professional organisations, trade unions and education bodies collaborate toward a shared goal maintaining high and consistent standards across the board. The use of established stakeholders such as the BMJ Group provided resources and platforms with high penetration and across all medical specialisms in England. The wide reach of BMJ publications, as well as recognised CPD accreditation, explains some of the high uptake and completion of eLearning modules, and we understand that using such platforms may not be feasible in every location, although it emphasises the advantage of using established media rather than radically new dissemination platforms.

In terms of evaluating the effectiveness of the programme, the focus is on its impact on confidence and capability to provide brief advice, as there is already a clear and consistent evidence base supporting brief advice from healthcare professionals on physical activity leading to improved rates of physical activity uptake in patients [36]. However, issues of objectivity and impartiality in the evaluation could arise when a single agency oversees the process. To minimise this bias, the evaluation of the MHPP has been delegated to independent academics at the University of Loughborough and Sheffield Hallam University, so we are therefore unable to conclude on the effectiveness of the MHPP. The challenge of evaluating multiple interventions across different stakeholders remains, and this complexity may yet affect the validity of the evaluation. Yet the evaluation will add to our understanding of the optimal educational model, shed light on the interconnectivity between components of the programme, the differential impact with different groups of clinicians and specific barriers emerging.

\section{Conclusions}

This technical paper sets out a novel whole system educational approach to embed routine brief advice on physical activity into every day clinical practice. The approach used could provide a model for future public health actions aiming to promote cultural changes and shift educational paradigms. However, future success will depend on objectively recognising, evaluating and addressing the barriers and facilitators to the implementation process. The initial engagement with the programme has been significant but time and further analysis will tell if the upstream implementation of the programme is achieving its goal of major cultural change among practitioners and the ultimate outcome of supporting more people to get active every day in England.

\section{Abbreviations}

BMJ: British Medical Journal; CPD: continuing professional education; FSEM: Faculty of Sports \& Exercise Medicine; GP: general practitioner; HCA: healthcare assistant; HCP: healthcare professional; MHPP: Moving Healthcare Professional programme; PHE: Public Health England

\begin{abstract}
Acknowledgements
The authors would like to acknowledge the National Centre for Sports and Exercise Medicine who are leading the external evaluation of the physical activity Moving Professionals Programme. We would also like to acknowledge the contribution of Nick Clarke and Tim Chapman, who have led elements of the programme as project management over the last two years, and the support from Prof. Gina Radford, Dr. William Bird, Prof. Steve Rodnic and our external advisory boards. We would also like to thank our delivery partners the Faculty of Sports and Exercise Medicine, Exercise Works, Nottingham University and Health Education England.
\end{abstract}

\section{Funding}

The programme was funded by PHE. In addition, the MHPP receives funding from Sport England and the Burdett Trust, as well as the Department for Work and Pensions (DWP) and Department of Health (DoH) Joint Unit on Health and Work. Only PHE was involved in the study design, data collection, analysis and writing of this manuscript. The authors receive no direct financial benefit from this investment.

Availability of data and materials

Data sets can be made available by PHE upon request.

\section{Authors' contributions}

$J V$ conceptualized the Moving Professionals Programme and developed the programme with the support of $\mathrm{MBr}$. MBe led the coordination of the article and the evidence review. All authors read and approved the final manuscript.

\section{Ethics approval and consent to participate}

The MHPP was approved by Public Health England Research Ethics Committee (PHE REC). The data presented in this manuscript was collected after obtaining informed written consent from all participants that completed eLearning modules and/or face-to-face training as part of the MHPP.

\section{Competing interests}

The authors declare they have no financial competing interests. JV conceptualised the MHPP programme and all three authors have been involved in the delivery of the programme. 


\section{Publisher's Note}

Springer Nature remains neutral with regard to jurisdictional claims in published maps and institutional affiliations.

\section{Author details}

'Public Health England, London, UK. ${ }^{2}$ Imperial College Healthcare NHS Trust, London, UK. ${ }^{3}$ Public Health, Birmingham City Council, Birmingham, UK.

Received: 2 May 2018 Accepted: 11 March 2019

Published online: 15 March 2019

\section{References}

1. Gordon L, Graves N, Hawkes A, Eakin E. A review of the cost-effectiveness of face-to-face behavioural interventions for smoking, physical activity, diet and alcohol. Chronic IIIn. 2007:3:101-29.

2. McPhail S, Schippers M. An evolving perspective on physical activity counselling by medical professionals. BMC Fam Pract. 2012;13:31.

3. Carroll JK, Winters PC, Sanders MR, Decker F, Ngo T, Sciamanna CN Clinician-targeted intervention and patient-reported counseling on physical activity. Prev Chronic Dis. 2014;11:E89.

4. Loprinzi PD, Beets MW. Need for increased promotion of physical activity by healthcare professionals. Prev Med. 2014;69:75-9.

5. HinrichsT MA, Klaaßen-Mielke R, Trampisch U, Thiem U, Platen P. General practitioner advice on physical activity: analyses in a cohort of older primary health care patients (getABI). BMC Fam Pract. 2011;12:26.

6. Bardach SH, Schoenberg NE. The content of diet and physical activity consultations with older adults in primary care. Patient Educ Couns. 2014; 95(3):319-24.

7. Hansen D, Rovelo Ruiz G, Doherty P, lliou MC, Vromen T, Hinton S, Frederix I, Wilhelm M, Schmid JP, Abreu A, Ambrosetti M, Garcia-Porrero E, Conin K, Dendale $P$, on behalf of the EAPC EXPERT working group. Do clinicians prescribe exercise similarly in patients with different cardiovascular diseases? Findings from the EAPC EXPERT working group survey. Eur I Prev Cardiol. 2018;25(7):682-91.

8. Bohm CJ, Storsley LJ, Hiebert BM, Nelko S, Tangri N, Cheskin LJ, McAdamsDeMarco MA, Rigatto C. Impact of exercise counseling on physical function in chronic kidney disease: an observational study. Can J Kidney Health Dis. 2018;5:1-11.

9. Bock C, Diehm C, Schneider S. Physical activity promotion in primary health care: results from a German physician survey. Eur J Gen Pract. 2012;18:86-91.

10. Carroll JK, Antognoli E, Flocke SA. Evaluation of physical activity counseling in primary care using direct observation of the 5As. Ann Fam Med. 2011; 9(5):416-22.

11. Delgado C, Johansen KL. Deficient counseling on physical activity among nephrologists. Nephron Clin Pract. 2010;116:C330-6.

12. Weiler R, Chew S, Coombs N, Hamer M, Stamataki E. Physical activity education in the undergraduate curricula of all UK medical schools. Are tomorrow's doctors equipped to follow clinical guidelines? Br J Sports Med. 2012:46:1-3.

13. Lowe A, Littlewood C, McLean S, Kilner K. Physiotherapy and physical activity: a cross-sectional survey exploring physical activity promotion, knowledge of physical activity guidelines and the physical activity habits of UK physiotherapists. BMJ Open Sport Exerc Med. 2017;3:e000290.

14. Lowe A, Gee M, McLean S, Littlewood C, Lindsay C, Everett S. Physical activity promotion in physiotherapy practice: a systematic scoping review of a decade of literature. Br J Sports Med. 2018:52:122-7.

15. Freene N, Cools S, Bissett B. Are we missing opportunities? Physiotherapy and physical activity promotion: a cross-sectional survey. BMC Sports Sci Med Rehabil. 2017;9:19.

16. Brotons C, Drenthen AJ, Durrer D, Moral I, European Network on Prevention and Health Promotion (EUROPREV). Beliefs and attitudes to lifestyle, nutrition and physical activity: the views of patients in Europe. Fam Pract. 2012;29(s1):i49-55.

17. AuYoung M, Linke SE, Pagoto S, Buman MP, Craft LL, Richardson CR, Hutber A, Marcus BH, Estabrooks P, Sheinfeld Gorin S. Integrating physical activity in primary care practice. Am J Med. 2016;129(10):1022-9.

18. Leemrijse CJ, de Bakker DH, Ooms L, Veenhof C. Collaboration of general practitioners and exercise providers in promotion of physical activity a written survey among general practitioners. BMC Fam Pract. 2015;16:96.
19. Laine J, Kuvaja-Köllner V, Pietilä E, Koivuneva M, Valtonen H, Kankaanpää E. Cost-effectiveness of population-level physical activity interventions: a systematic review. Am J Health Promot. 2014;29(2):71-80.

20. Cobiac $L$, Vos T, Barendregt JJ. Cost-effectiveness of interventions to promote physical activity: a modelling study. PLoS Med. 2009;6(7):e1000110.

21. Müller-Riemenschneider RT, Willich SN. Cost-effectiveness of interventions promoting physical activity. Br J Sports Med. 2009:43:70-6.

22. Lobelo F, Duperly J, Frank E. Physical activity habits of doctors and medical students influence their counselling practices. Br J Sports Med. 2009:43:89-92.

23. Nelson A, de Normanville C, Payne K, Kelly MP. Making every contact count: an evaluation. Public Health. 2013;127(7):653-60

24. Lawrence W, Black C, Tinati T, Cradock S, Begum R, Jarman M, Pease A, Margetts B, Davies J, Inskip H, Cooper C, Baird J, Barker M. 'Making every contact count': evaluation of the impact of an intervention to train health and social care practitioners in skills to support health behaviour change. J Health Psychol. 2016;21(2):138-51.

25. Bird W. Physical activity in the treatment of long term conditions. BMJ learning, Release date 22/10/2014. http://learning.bmj.com/learning/courseintro/physicalactivity.html?courseld=10051913\&locale=en_GB. Accessed 14 Mar 2019.

26. Chopra M, Galbraith S, Darnton-Hill I. A global response to a global problem: the epidemic of over nutrition. Bull World Health Organ. 2002;80: 952-8.

27. Phillips E, Pojednic R, Polak R, Bush J, Trilk J. Including lifestyle medicine in undergraduate medical curricula. Med Educ Online. 2015;20:26150.

28. World Health Organisation (WHO). Physical activity for health. More active people for a healthier world: draft global action plan on physical activity 2018-2030. WHO Discussion paper, December 2017. http://www.who.int/ ncds/governance/Global-action-plan-on-PA-DRAFT-2-Dec-2017.pdf?ua=1. Accessed 14 Mar 2019.

29. Solmundson K, Koehle M, McKenzie D. Exercise medicine in residency: are we preparing future family physicians to prescribe exercise as medicine? Canadian Family Physician Conference: Family Medicine Forum, FMF 2016 Canada. 63 (2 Supplement 1) (pp S76), 2017. Date of Publication: February 2017.

30. Harden RM. What is a spiral curriculum? Med Teach. 1999;21(2):141-3.

31. George PP, Papachristou N, Belisario JM, Wang W, Wark PA, Cotic Z, Rasmussen K, Sluiter R, Riboli-Sasco E, Tudor Car L, Musulanov EM, Molina JA, Heng BH, Zhang Y, Wheeler EL, Al Shorbaji N, Majeed A, Car J. Online eLearning for undergraduates in health professions: a systematic review of the impact on knowledge, skills, attitudes and satisfaction. J Glob Health. 2014:4(1):010406.

32. Maloney S, Nicklen P, Rivers G, Foo J, Ooi YY, Reeves S, Walsh K, llic D. A cost-effectiveness analysis of blended versus face-to-face delivery of evidence-based medicine to medical students. J Med Internet Res. 2015; 17(7):e182.

33. Richards EA, Cai Y. Physical activity outcomes of nurse-delivered lifestyle interventions. Home Healthcare Now. 2016:34(2):93-101.

34. Verwey $\mathrm{R}$, van der Weegen $\mathrm{S}$, Spreeuwenberg $\mathrm{M}$, Tange $\mathrm{H}$, van der Weijden T, de Witte L. Upgrading physical activity counselling in primary care in the Netherlands. Health Promot Int. 2016;31(2):344-54.

35. Sinclair PM, Kable A, Levett-Jones T, Booth D. The effectiveness of internetbased e-learning on clinician behaviour and patient outcomes: a systematic review. Int J Nurs Stud. 2016;57:70-81.

36. National Institute for Clinical Excellence (NICE). Physical activity: brief advice for adults in primary care. Public health guideline, May 2013. www.nice.org. uk/guidance/ph44. Accessed 5 Nov 2018.

Ready to submit your research? Choose BMC and benefit from:

- fast, convenient online submission

- thorough peer review by experienced researchers in your field

- rapid publication on acceptance

- support for research data, including large and complex data types

- gold Open Access which fosters wider collaboration and increased citations

- maximum visibility for your research: over $100 \mathrm{M}$ website views per year

At $\mathrm{BMC}$, research is always in progress.

Learn more biomedcentral.com/submission 